Article

\title{
The Effect of Cannabidiol on Psychosis-like Behaviour Induced by Methamphetamine and MK-801 in Mice: A Negative Report
}

Emily J. Jaehne, Maarten van den Buuse*

School of Psychology and Public Health, La Trobe University, Melbourne, Victoria 3086, Australia

* Correspondence: Maarten van den Buuse, Email: m.vandenbuuse@latrobe.edu.au; Tel.: +61-3-94795257.

\begin{abstract}
Background: Cannabis is a widely used illicit substance but may also have medicinal properties. Cannabidiol (CBD), one of the main compounds of interest in the cannabis plant, has been suggested to have beneficial effects in various psychiatric disorders including anxiety and psychosis. Drug-induced locomotor hyperactivity is a commonly used animal model of psychosis-like behaviour and to show antipsychotic drug action. Several genetic and developmental animal models of psychosis show differences in locomotor hyperactivity. The aim of the present study was to investigate the effect of pretreatment with CBD on psychosis-like behaviour in mice.
\end{abstract}

Methods: The animals underwent 5 sessions of locomotor activity testing each, with 3-4 days between tests to allow washout of acute drug challenge. Groups of mice ( $n=8$ male mice and $n=8$ female mice combined) were pretreated with CBD $(10 \mathrm{mg} / \mathrm{kg})$ or its vehicle, followed $1 \mathrm{~h}$ later with either saline, the dopamine releaser, methamphetamine (1 or $3 \mathrm{mg} / \mathrm{kg}$ ), or the NMDA receptor antagonist, MK-801 (0.1 or $0.25 \mathrm{mg} / \mathrm{kg}$ ).

Results: There was no significant effect of CBD on its own on locomotor activity. Pretreatment with CBD had no effect on the hyperlocomotion induced by either dose of methamphetamine. There was also no effect of CBD on MK-801 induced hyperlocomotion following the $0.25 \mathrm{mg} / \mathrm{kg}$ dose, while $0.1 \mathrm{mg} / \mathrm{kg}$ MK-801 did not induce hyperactivity.

Conclusions: These results do not support an antipsychotic action of CBD.

KEYWORDS: cannabinoids; psychosis; antipsychotics; methamphetamine; mice; dopamine; cannabidiol

\section{ABBREVIATIONS}

ANOVA, ANALYSIS OF VARIANCE; CBD, cannabidiol; Meth, methamphetamine; NMDA, $N$-methyl-D-aspartate; SEM, standard error of the mean; THC, $\Delta 9$-tetrahydrocannabinol 


\section{INTRODUCTION}

Cannabis is the most widely used illicit substance in the world, with at least $3.4 \%$ of people reporting use during 2016 worldwide [1]. While the cannabis plant contains many hundreds of compounds [2], the two main compounds of interest are $\Delta 9$-tetrahydrocannabinol (THC) and cannabidiol (CBD). There is also growing interest in the medicinal effects of cannabis, such as in neurological and psychitric illness. Schizophrenia and psychosis, including drug-induced psychosis, are devastating mental illnesses which place a huge burden on the individual, their relatives, and society at large [3-5]. Treatment options are limited and a better understanding of the brain mechanisms involved might lead to novel treatments. Although THC in particular has been implicated in the development of psychosis or schizophrenia [6,7], several recent reviews have suggested that CBD may be beneficial in a number of psychiatric disorders including psychosis [8-10]. However, there is substantial variability in experimental power, methodology, dosing and experimental protocols used, and the mechanism of any antipsychotic-like effect of CBD remains unclear. A systematic review showed that in fact only few studies report reduction of psychotic symptoms in patients with schizophrenia where the effect could not be explained simply by CBD counteracting the psychotic effects of cannabis or THC [11]. Therefore, it is clear that further studies are needed to clarify the antipsychotic potential of CBD [12].

In animal model studies of antipsychotic drug action, psychotropic drug-induced increases in locomotor activity have been used widely as a model of psychosis-like behaviour [13,14]. Typically, rats or mice are tested in an open field or automated locomotor photocells and, after an initial habituation period, injected with a dopamine releasing drug, such as amphetamine or methamphetamine, or a glutamate $N$-methyl-D-aspartate (NMDA) receptor antagonist, such as phencyclidine or MK-801 [13,15]. The ensuing locomotor hyperactivity is quantified and animals can be tested on multiple occasions if sufficient drug wash-out is allowed for, thus enabling them to serve as their own controls. Subtle differences in responding can be found in animals which have been genetically-modified for relevant gene function, have received developmental pretreatments, or are pretreated acutely with experimental compounds [13,15]. We have previously used this approach for all of these scenarios [16-20].

Previous locomotor hyperactivity studies in rats and mice have shown variable effects of CBD, with some showing an effect of lower but not higher doses, others only higher doses, while some have looked at acute doses and others following repeated administration [8,12] (see also Discussion). In the present study we used our standard protocols and investigated the effect of acute administration of a moderate dose of CBD to antagonize the locomotor hyperactivity induced by treatment with methamphetamine or MK-801. 


\section{MATERIALS AND METHODS}

\section{Animals}

C57BL/6 mice were purchased from WEHI and transferred to the La Trobe Animal Research and Teaching Facility (LARTF). A total of 32 male and female mice were used for experiments ( $n=16$ /group, 8 male +8 female). All mice were housed in groups of 4 during the experimental period in individually ventilated cages (Techniplast, Buguggiate, Italy) with food and water available ad libitum. Ambient temperature of housing and testing rooms was $21 \pm 2{ }^{\circ} \mathrm{C}$ and mice were housed under a 12-h light-dark cycle, lights on at 07:00 $\mathrm{h}$, with all behavioural testing conducted between 08:00 and 16:00 h. All experimentation was approved by the La Trobe University Animal Ethics Committee and was conducted in accordance with the Australian Code of Practice for the Care and Use of Animals for Scientific Purposes set out by the National Health and Medical Research Council of Australia. Project ID was AEC17-55 (approval date 18 September 2017).

\section{Drugs}

Cannabidiol (CBD) was first dissolved in $100 \%$ ethanol then diluted to a concentration of $2 \mathrm{mg} / \mathrm{mL}$ in Tween 80 and $0.9 \%$ sterile saline at a ratio of 1:1:18 (Tween 80:ethanol:saline). CBD was administered at a dose volume of $5 \mathrm{~mL} / \mathrm{kg}$ to give a final dose of $10 \mathrm{mg} / \mathrm{kg}$. This dose was based on previous studies [21,22]. (+)-MK-801 hydrogen maleate (MK-801; 0.1 and $0.25 \mathrm{mg} / \mathrm{kg}$ ) and methamphetamine (Meth; 1 and $3 \mathrm{mg} / \mathrm{kg}$ ) were dissolved in $0.9 \%$ sterile saline and also given at a dose volume of $5 \mathrm{~mL} / \mathrm{kg}$. These doses were based on previous work in our lab showing reliable hyperactivity [16-20].

CBD and methamphetamine were supplied by the National Measurement Institute (Pymble, NSW, Australia). MK-801 and Tween 80 were purchased from Sigma-Aldrich (Merck KGaA, Darmstadt, Germany).

\section{Experimental Procedure}

Mice underwent five sessions of locomotor activity testing each, with 3-4 days between tests to allow washout of acute challenge drug. Mice were first administered CBD or its vehicle before being placed into automated photocell arenas (Med Associates, Fairfax, VT, USA). These arenas were $27 \times 27 \mathrm{~cm}$ with walls $40 \mathrm{~cm}$ high, with a $16 \times 16$ array of photobeam sensors for detecting movement.

Mice were allocated to either the CBD group or saline group and thus received the same pretreatment prior to each locomotor activity session. During each of five sessions, mice were first pretreated, then placed in the arena for $1 \mathrm{~h}$ to habituate, after which they were removed briefly and injected with the challenge drug, and then placed back into the arena for

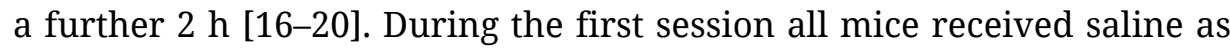
the challenge. In the second session mice received either $1 \mathrm{mg} / \mathrm{kg}$ 
methamphetamine or $0.1 \mathrm{mg} / \mathrm{kg}$ MK-801 and in the third session they received $3 \mathrm{mg} / \mathrm{kg}$ or $0.25 \mathrm{mg} / \mathrm{kg}$, respectively, of the same drug. In Sessions 4 and 5 mice received the opposite drug to Sessions 2 and 3, with the lower dose again given first. Distance travelled was automatically calculated in 5-min time bins.

\section{Analysis}

Data was expressed as the mean \pm standard error of the mean (SEM) and differences between groups were analysed with analysis of variance (ANOVA) with repeated measures where appropriate using IBM SPSS Statistics 23 (Armonk, NY, USA). For all data between-group statistical factors were CBD treatment and sex. Within-group repeated-measures factors were time and acute methamphetamine or MK-801 treatment.

One mouse from each treatment group was excluded from methamphetamine analysis due to low activity indicating ineffective injection of methamphetamine. One additional mouse was also excluded from all analyses due to very high activity during the saline baseline session. Although there was a significant main effect of sex for all analyses, as females are generally more active than males, there were no interactions of sex of the animals with CBD or challenge drug treatments; therefore all data are presented in the results as sexes combined.

Differences between groups were considered significant at $p<0.05$. All data are expressed as mean \pm standard error of the mean (SEM).

\section{RESULTS}

\section{Effect of CBD on Baseline Locomotor Activity}

To assess effects of acute CBD and vehicle treatment in the first hour following injection, the average locomotor activity was calculated for during the habituation period of all five sessions (Figure 1A). There was no difference in activity during this time (main effect CBD, $p=0.48$ ), however there was a difference in the time course of activity (time $\times$ drug interaction, $p<0.05)$. Inspection of the graph suggested that this result is likely due to slightly higher activity in the mice allocated to the CBD treatment although this occurred mainly in the first $10 \mathrm{~min}$, when the drug would not be expected to be active.

To further assess the acute effects of CBD and vehicle treatment on baseline locomotor activity, we assessed the effect of saline injection during the first session (Figure 1B). Again there were no differences in activity between $\mathrm{CBD}$ and vehicle-treated mice following saline injection given $1 \mathrm{~h}$ after pretreatment (main effect CBD, $p=0.73$, time $\times$ drug interaction, $p=0.66$ ).

Taken together, these results show that there were no effects of CBD pretreatment on baseline locomotor activity which could have masked any possible interactions with either methamphetamine or MK-801. 

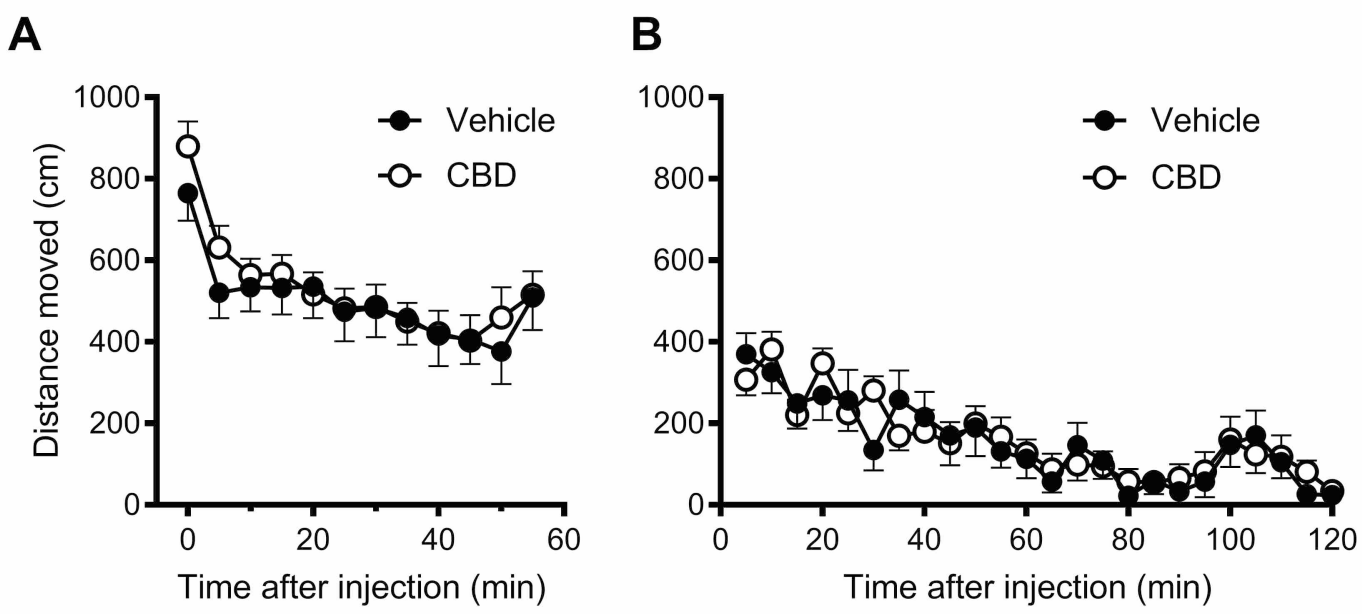

Figure 1. (A) Locomotor activity during the 1st hour immediately following CBD or vehicle injection. Average value of all five sessions was calculated for each mouse. (B) Locomotor activity following saline control injection given 1 hour after CBD or vehicle injection.

\section{Effect of CBD on Methamphetamine-Induced Locomotor Hyperactivity}

Analysis of locomotor activity following 1 and $3 \mathrm{mg} / \mathrm{kg}$ methamphetamine compared to saline control (Figure 2A) showed a significant main effect of an acute methamphetamine challenge $(p<0.001)$ and a methamphetamine $\times$ CBD $\times$ time interaction $(p=0.001)$. Additional ANOVAs were therefore done to compare the effect of each dose of acute methamphetamine with saline treatment to further explore this relationship. Following acute injection with $1 \mathrm{mg} / \mathrm{kg}$ methamphetamine, there was a significant main effect of treatment compared to saline injection $(p=0.023)$. However there was no interaction with CBD (meth $\times$ $\mathrm{CBD}, p=0.69$ ) or over time (meth $\times \mathrm{CBD} \times$ time, $p=0.69$ ), indicating that, although methamphetamine increased activity compared to saline injection, pretreatment with CBD had no effect on methamphetamine response at this dose.

Following acute injection with $3 \mathrm{mg} / \mathrm{kg}$ methamphetamine, analysis again showed a significant main effect of treatment compared to saline injection $(p<0.001)$. Again, there was no interaction with CBD pretreatment (meth $\times \mathrm{CBD}, p=0.85$ ), however there was a difference in the time course of activity (meth $\times \mathrm{CBD} \times$ time, $p=0.007$ ). Investigation of the graph suggests that this was due to slightly higher activity in CBD-pretreated mice during the first hour, but slightly lower activity during the 2nd hour post-methamphetamine injection, when activity plateaus at a low level. However, further analysis of distance moved during the first or second hour post-methamphetamine separately showed that while there was a significant main effect of methamphetamine (1st hour: $p<0.001$, 2nd hour: $p<0.01$ ), there was no interaction with CBD (meth $\times$ CBD interaction 1st hour: $p=0.43$, 2nd hour: 
$p=0.88$ ). Total distance travelled in the first hour was $2799 \pm 576$ and $2381 \pm 318 \mathrm{~cm}$ following acute saline injection and $13404 \pm 2133$ and $16759 \pm 2246 \mathrm{~cm}$ following acute methamphetamine injection in vehicle and CBD-pretreated mice, respectively. Total distance travelled in the second hour was $1024 \pm 268$ and $1113 \pm 220 \mathrm{~cm}$ following saline and $8644 \pm 1159$ and $6407 \pm 828 \mathrm{~cm}$ following methamphetamine in vehicle and CBD-pretreated mice, respectively. Post-hoc analysis at each individual time point also did not reveal any significant difference between saline controls and CBD-pretreated mice (data not shown).
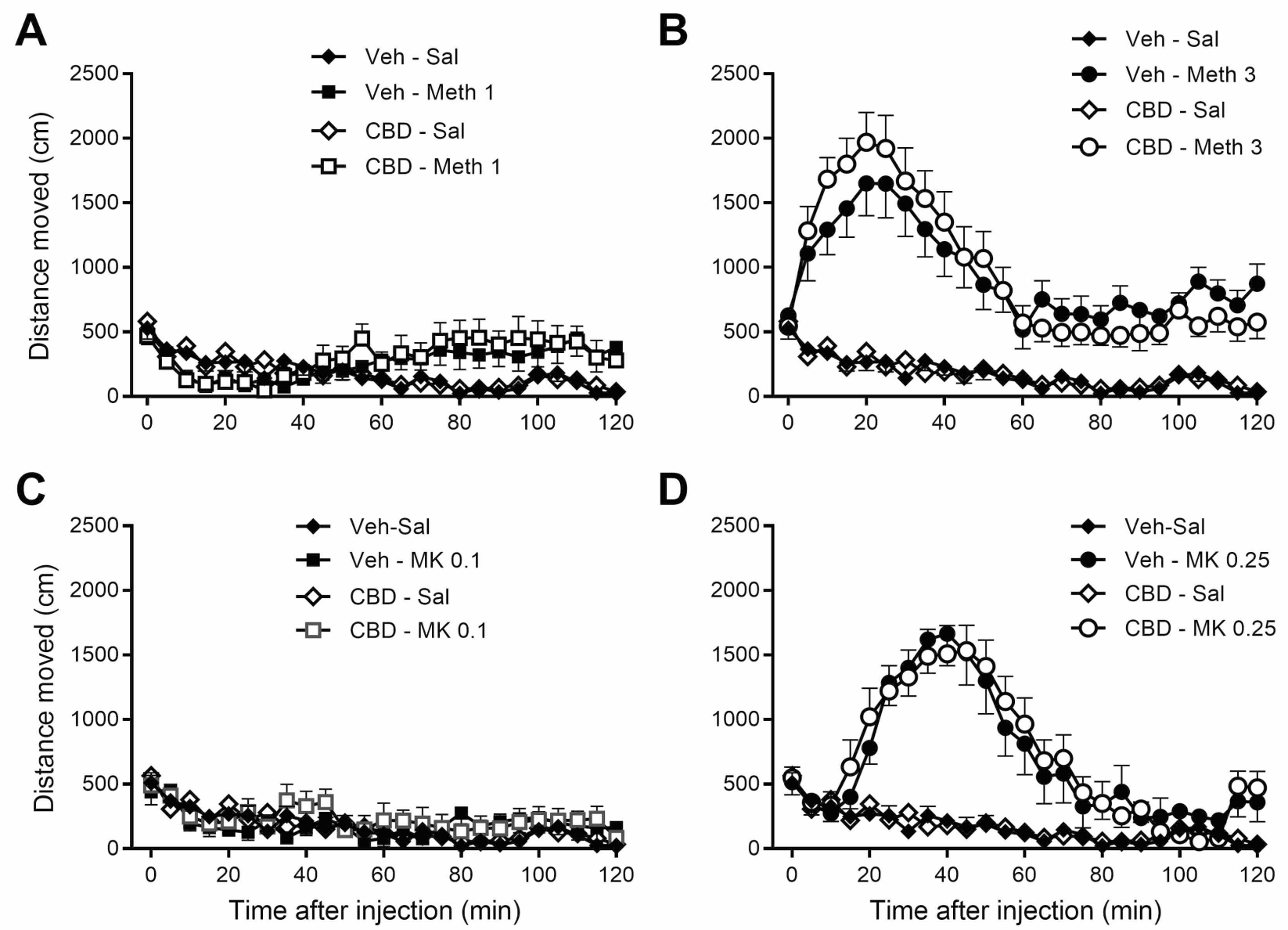

Figure 2. Locomotor activity following saline control vs. methamphetamine (Meth) $1 \mathrm{mg} / \mathrm{kg}$ (A) or $3 \mathrm{mg} / \mathrm{kg}$ (B) injection, or MK-801 (MK) $0.1 \mathrm{mg} / \mathrm{kg}$ (C) or $0.25 \mathrm{mg} / \mathrm{kg}$ (D) injection given $1 \mathrm{~h}$ after CBD or vehicle injection. Note saline data are the same in all panels and included for comparison.

\section{Effect of CBD on MK-801-Induced Locomotor Hyperactivity}

Analysis of locomotor activity following 0.1 and $0.25 \mathrm{mg} / \mathrm{kg}$ MK-801 compared to saline control (Figure 2B) showed a significant main effect of the acute MK-801 challenge $(p<0.001)$. Further ANOVAs were therefore done to compare the effect of each dose of acute MK-801 vs. saline to further explore this relationship.

Following acute injection with $0.1 \mathrm{mg} / \mathrm{kg} \mathrm{MK}-801$, there was no 
significant effect of treatment compared to saline injection ( $p=0.22$ ), indicating this dose did not have an effect on locomotor activity. Following acute injection with $0.25 \mathrm{mg} / \mathrm{kg}$ MK-801, there was a significant main effect of treatment compared to saline injection $(p<0.001)$. However there was no interaction with CBD (MK-801 $\times$ CBD, $p=0.91)$ or over time (MK-801 $\times$ CBD $\times$ time, $p=0.81$ ), indicating pretreatment with CBD had no effect on the MK-801 response at either dose.

\section{DISCUSSION}

This study showed that there was no significant effect of $10 \mathrm{mg} / \mathrm{kg}$ CBD on its own on locomotor activity, either during the first hour prior to any subsequent drug challenges, or for the $2 \mathrm{~h}$ following a saline control injection at $1 \mathrm{~h}$ post-CBD. This suggests that any possible effects of CBD we may have seen on responses to methamphetamine or MK-801 would likely have been due to a specific interaction between $\mathrm{CBD}$ and the challenge drug, and not just a sedating effect of CBD. Previous studies have shown that the same $10 \mathrm{mg} / \mathrm{kg}$ dose we used decreased locomotor activity in mice in a light dark test but not in an open field [23] and also decreased prepulse inhibition [PPI] in untreated rats [21], while both higher and lower doses have shown no effect on baseline locomotor activity in mice [23-25] and 1 but not $3 \mathrm{mg} / \mathrm{kg}$ CBD decreased locomotor activity in untreated rats [26].

A range of preclinical studies have investigated the effects of CBD on animal models of psychosis-like behaviour with variable results. Studies using MK-801-induced disruption of PPI as a model of psychosis-related behaviour have shown that an acute dose of 5, but not 1 or $15 \mathrm{mg} / \mathrm{kg}$ CBD was able to reverse the effects of MK-801 in mice [22], while doses of 3, 10 and $30 \mathrm{mg} / \mathrm{kg}$ had no effect in rats [21]. Further studies have shown CBD 30 and 60 , but not $15 \mathrm{mg} / \mathrm{kg}$, also attenuated the disruptive effect of amphetamine on PPI in mice [27]. The effect of chronic treatment with CBD has also been investigated in mice also treated chronically with MK-801 and showed that CBD 30 and 60 but not $15 \mathrm{mg} / \mathrm{kg}$ attenuated the MK-801 induced disruption of PPI, however a single dose of CBD at any dose had no effect [28].

Studies using acute administration of CBD prior to a stimulant have shown that both 1 and $3 \mathrm{mg} / \mathrm{kg}$ were able to inhibit MK-801 induced hyperactivity in rats [26], while 30 and 60 , but not $15 \mathrm{mg} / \mathrm{kg}$, reversed D-amphetamine-induced hyperactivity and 30, but not 15 or $60 \mathrm{mg} / \mathrm{kg}$, attenuated ketamine-induced activity increases in mice [25]. Following chronic treatment with CBD for 21 days in mice, a $50 \mathrm{mg} / \mathrm{kg}$ dose, but not 1 or $5 \mathrm{mg} / \mathrm{kg}$, was able to attenuate D-amphetamine-induced hyperlocomotion, however an acute dose was not effective [23]. These previous studies illustrate the highly variable effect of CBD in previous studies on rodent models of psychosis-like behaviour. We aimed to re-evaluate the effect of a moderate dose of CBD using protocols which in 
our previous studies have shown clear differences between mouse groups with different genotypes or pretreatments [16-20].

Our results show that pretreatment with $10 \mathrm{mg} / \mathrm{kg}$ CBD did not attenuate the hyperlocomotion induced by either 1 or $3 \mathrm{mg} / \mathrm{kg}$ methamphetamine, although it did appear to slightly alter the time course of the response to the $3 \mathrm{mg} / \mathrm{kg}$ dose. This is somewhat similar to a previous study which showed that an acute dose of 1 or $50 \mathrm{mg} / \mathrm{kg}$ CBD given $45 \mathrm{~min}$ before a D-amphetamine challenge also did not alter locomotor hyperactivity, while CBD $50 \mathrm{mg} / \mathrm{kg}$, but not 1,5 or $10 \mathrm{mg} / \mathrm{kg}$, given daily for 21 days was only able to attenuate the effect of D-amphetamine at 35-45 min post-challenge [23]. Both results are in contrast to another study which showed that 30 and 60 , but not $15 \mathrm{mg} / \mathrm{kg}$, CBD given 20 min before D-amphetamine was able to significantly reverse the effects of this challenge in Swiss mice [25]. It is possible that these differences can be explained by the different strains of mice used, as Pedrazzi et al. [27] also showed the same doses of CBD given $30 \mathrm{~min}$ before amphetamine were able to attenuate the PPI disrupting effects of amphetamine in Swiss mice.

We also showed no effect of CBD on MK-801-induced hyperlocomotion following the $0.25 \mathrm{mg} / \mathrm{kg}$ dose. This is in contrast to Gururajan et al. [26] who showed that lower doses of 1 and $3 \mathrm{mg} / \mathrm{kg}$ CBD were able to inhibit the locomotor hyperactivity induced by $0.3 \mathrm{mg} / \mathrm{kg}$ MK-801 given $20 \mathrm{~min}$ later. While this study was conducted in a different species and with different doses on CBD, it is also worth noting that the time period between CBD and MK-801 administration was shorter than the 1 hour period used in the current study and could contribute to the lack of effects seen in our study. Additional studies have also used a similar 20-min time period between CBD and MK-801 administration in PPI experiments, and showed that $5 \mathrm{mg} / \mathrm{kg}$ CBD was able to reverse the PPI disrupting effect of $1 \mathrm{mg} / \mathrm{kg}$ MK-801 [22] in mice, however using the same protocol 3, 10 and $30 \mathrm{mg} / \mathrm{kg}$ CBD had no effect on the disruption of PPI induced by MK-801 in rats [21].

Limitations of this study include the lack of a positive control to verify that the CBD was effective in some conditions while having no effect of psychosis-like behaviour in the mice. Further studies could also be done with shorter time-intervals between CBD and methamphetamine/MK-801 injection. It is unlikely that the lack of effect of CBD in our study is caused by lack of statistical power. The numbers of animals per group used here are comparable to several of our previous studies where highly significant changes in psychosis-like behaviour could be found (see above for references). Moreover, other than a slight change in the time-course of behaviour there were no clear trends that could have reflected possible significant drug effects if more animals had been tested. 


\section{CONCLUSIONS}

We were unable to show an effect of $10 \mathrm{mg} / \mathrm{kg} \mathrm{CBD}$, given one hour prior, on the hyperlocomotion induced either by methamphetamine or MK-801 in mice, widely-used experimental indices of psychosis-like behaviour [13]. Experimental variables such as the dose and dosing protocol used, the strain of animal used, or the time period between CBD and subsequent stimulant drug, may play a role in these negative findings. Our study adds to the literature by failing to show a possible antipsychotic effects of CBD. Additional studies have shown promising effects of CBD when given to genetic animal models of psychosis-like behaviour including Nrg1 Het mice [24] and spontaneously hypertensive rats [29]. This suggests future studies may benefit from including genetic and developmental models of psychosis-like behaviour to further elucidate a possible role of $\mathrm{CBD}$ in the treatment of psychosis and schizophrenia.

\section{AUTHOR CONTRIBUTIONS}

EJ designed and did the experiments, analyzed the results, and wrote the first draft. MvdB obtained funding, co-designed the study, and edited and completed the manuscript.

\section{CONFLICTS OF INTEREST}

The authors have no conflicts of interest to declare.

\section{FUNDING}

These studies were supported by a seeding grant from the La Trobe University School of Psychology and Public Health Engagement Income Growth Grant Scheme. This funding source was not involved in study design, data collection and interpretation, manuscript preparation, or the decision to submit the work for publication.

\section{REFERENCES}

1. UNODC. World Drug Report 2018. Available from https://www.unodc.org/wdr2018/prelaunch/Pre-briefingAM-fixed.pdf. Accessed 2019 Mar 11.

2. Elsohly MA, Slade D. Chemical constituents of marijuana: the complex mixture of natural cannabinoids. Life Sci. 2005;78(5):539-48. doi: 10.1016/j.lfs.2005.09.011

3. McGrath J, Saha S, Chant D, Welham J. Schizophrenia: a concise overview of incidence, prevalence, and mortality. Epidemiol Rev. 2008;30:67-76. doi: 10.1093/epirev/mxn001

4. Sagut P, Çetinkaya Duman Z. Comparison of caregiver burden in first-episode versus chronic psychosis. Arch Psychiatr Nurs. 2016;30(6):768-73. doi: 10.1016/j.apnu.2016.07.011 
5. Vigo D, Thornicroft G, Atun R. Estimating the true global burden of mental illness. Lancet Psychiatry 2016;3(2):171-8. doi: 10.1016/S2215-0366(15)00505-2

6. Gage SH, Hickman M, Zammit S. Association between cannabis and psychosis: Epidemiologic evidence. Biol Psychiatry. 2016;79(7):549-56. doi: 10.1016/j.biopsych.2015.08.001

7. Shrivastava A, Johnston M, Terpstra K, Bureau Y. Pathways to psychosis in cannabis abuse. Clin Schizophr Relat Psychoses 2015;9(1):30-5. doi: 10.3371/CSRP.SHJO.030813

8. Gururajan A, Malone DT. Does cannabidiol have a role in the treatment of schizophrenia? Schizophr Res. 2016;176(2-3):281-90. doi: 10.1016/j.schres.2016.06.022

9. Hahn B. The potential of cannabidiol treatment for cannabis users with recent-onset psychosis. Schizophr Bull. 2018;44(1):46-53. doi: 10.1093/schbul/sbx105

10. Mandolini GM, Lazzaretti M, Pigoni A, Oldani L, Delvecchio G, Brambilla P. Pharmacological properties of cannabidiol in the treatment of psychiatric disorders: a critical overview. Epidemiol Psychiatr Sci. 2018;27(4):327-35. doi: $10.1017 /$ S2045796018000239

11. Iseger TA, Bossong MG. A systematic review of the antipsychotic properties of cannabidiol in humans. Schizophr Res. 2015;162(1-3):153-61. doi: 10.1016/j.schres.2015.01.033

12. Zuardi AW, Crippa JA, Hallak JE, Bhattacharyya S, Atakan Z, Martin-Santos R, McGuire PK, Guimaraes FS. A critical review of the antipsychotic effects of cannabidiol: 30 years of a translational investigation. Curr Pharm Des. 2012;18(32):5131-40.

13. van den Buuse M. Modeling the positive symptoms of schizophrenia in genetically modified mice: pharmacology and methodology aspects. Schizophr Bull. 2010;36(2):246-70. doi: 10.1093/schbul/sbp132

14. Young JW, Minassian A, Geyer MA. Locomotor profiling from rodents to the clinic and back again. Curr Top Behav Neurosci. 2016;28:287-303. doi: 10.1007/7854_2015_5015

15. van den Buuse M, Garner B, Gogos A, Kusljic S. Importance of animal models in schizophrenia research. Aust N Z J Psychiatry. 2005;39(7):550-7.

16. Adams W, Ayton S, van den Buuse M. Serotonergic lesions of the dorsal hippocampus differentially modulate locomotor hyperactivity induced by drugs of abuse in rats: implications for schizophrenia. Psychopharmacology (Berl). 2009;206(4):665-76. doi: 10.1007/s00213-009-1617-1

17. Chavez C, Gogos A, Jones ME, van den Buuse M. Psychotropic drug-induced locomotor hyperactivity and prepulse inhibition regulation in male and female aromatase knockout (ArKO) mice: role of dopamine D1 and D2 receptors and dopamine transporters. Psychopharmacology (Berl). 2009;206(2):267-79. doi: 10.1007/s00213-009-1604-6 
18. Manning EE, Halberstadt AL, van den Buuse M. BDNF-deficient mice show reduced psychosis-related behaviors following chronic methamphetamine. Int J Neuropsychopharmacol. 2016;19(4):pyv116. doi: 10.1093/ ijnp/pyv116

19. van den Buuse M, Ruimschotel E, Martin S, Risbrough VB, Halberstadt AL. Enhanced effects of amphetamine but reduced effects of the hallucinogen, 5-MeO-DMT, on locomotor activity in 5- $\mathrm{HT}_{1 \mathrm{~A}}$ receptor knockout mice: implications for schizophrenia. Neuropharmacology. 2011;61(1-2):209-16. doi: 10.1016/j.neuropharm.2011.04.001

20. van den Buuse M, Wischhof L, Lee RX, Martin S, Karl T. Neuregulin 1 hypomorphic mutant mice: enhanced baseline locomotor activity but normal psychotropic drug-induced hyperlocomotion and prepulse inhibition regulation. Int J Neuropsychopharmacol. 2009;12(10):1383-93. doi: $10.1017 /$ S1461145709000388

21. Gururajan A, Taylor DA, Malone DT. Effect of cannabidiol in a MK-801-rodent model of aspects of schizophrenia. Behav Brain Res. 2011;222(2):299-308. doi: 10.1016/j.bbr.2011.03.053

22. Long LE, Malone DT, Taylor DA. Cannabidiol reverses MK-801-induced disruption of prepulse inhibition in mice. Neuropsychopharmacology. 2006;31(4):795-803.

23. Long LE, Chesworth R, Huang XF, McGregor IS, Arnold JC, Karl T. A behavioural comparison of acute and chronic Delta9-tetrahydrocannabinol and cannabidiol in C57BL/6JArc mice. Int J Neuropsychopharmacol. 2010;13(7):861-76. doi: 10.1017/S1461145709990605

24. Long LE, Chesworth R, Huang XF, Wong A, Spiro A, McGregor IS, Arnold JC, Karl T. Distinct neurobehavioural effects of cannabidiol in transmembrane domain neuregulin 1 mutant mice. PLoS One 2012;7(4):e34129. doi: 10.1371/journal.pone.0034129

25. Moreira FA, Guimaraes FS. Cannabidiol inhibits the hyperlocomotion induced by psychotomimetic drugs in mice. Eur J Pharmacol. 2005;512(2-3):199-205.

26. Gururajan A, Taylor DA, Malone DT. Cannabidiol and clozapine reverse MK-801-induced deficits in social interaction and hyperactivity in Sprague-Dawley rats. J Psychopharmacol. 2012;26(10):1317-32. doi: 10.1177/ 0269881112441865

27. Pedrazzi JF, Issy AC, Gomes FV, Guimaraes FS, Del-Bel EA. Cannabidiol effects in the prepulse inhibition disruption induced by amphetamine. Psychopharmacology (Berl). 2015;232(16):3057-65. doi: 10.1007/ s00213-015-3945-7

28. Gomes FV, Llorente R, Del Bel EA, Viveros MP, Lopez-Gallardo M, Guimaraes FS. Decreased glial reactivity could be involved in the antipsychotic-like effect of cannabidiol. Schizophr Res. 2015;164(1-3):155-63. doi: 10.1016/ j.schres.2015.01.015 
29. Levin R, Peres FF, Almeida V, Calzavara MB, Zuardi AW, Hallak JE, Crippa JA, Abilio VC. Effects of cannabinoid drugs on the deficit of prepulse inhibition of startle in an animal model of schizophrenia: the SHR strain. Front Pharmacol. 2014;5:10. doi: 10.3389/fphar.2014.00010

How to cite this article:

Jaehne EJ, van den Buuse M. The effect of cannabidiol on psychosis-like behaviour induced by methamphetamine and MK-801 in mice: A Negative Report. J Psychiatry Brain Sci. 2019;4:e190006. https://doi.org/10.20900/jpbs.20190006 